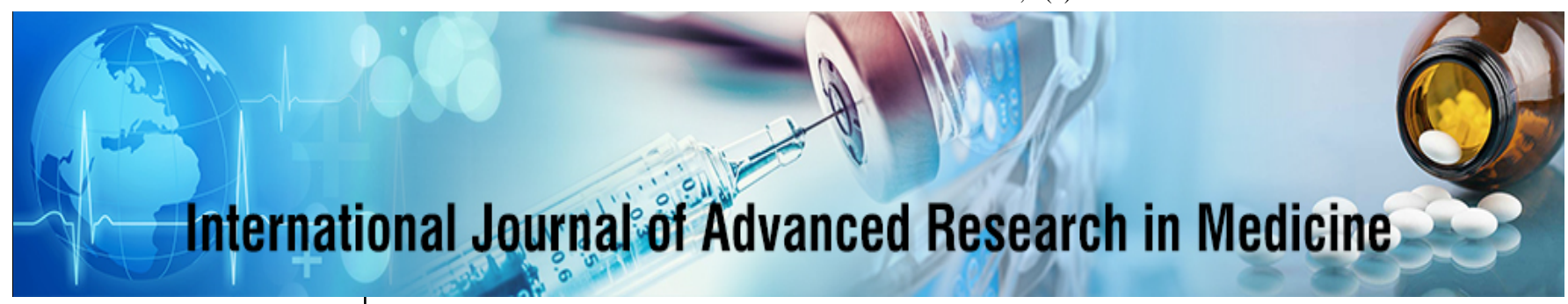

E-ISSN: 2706-9575

P-ISSN: 2706-9567

IJARM 2020; 2(2): 282-290

Received: 02-12-2020

Accepted: 25-12-2020

Dr. P Chudamani

Assistant Professor,

Department of General

Medicine, NRI Medical College

\& Hospital Chinakakani,

Guntur, Andhra Pradesh, India

Corresponding Author: Dr. P Chudamani

Assistant Professor,

Department of General

Medicine, NRI Medical College

\& Hospital Chinakakani,

Guntur, Andhra Pradesh,

India

\section{Comparative study of pulmonary tuberculosis in diabetics and non-diabetics}

\section{Dr. P Chudamani}

DOI: https://doi.org/10.22271/27069567.2020.v2.i2d.243

\begin{abstract}
Background: The frequent association of diabetes mellitus and pulmonary tuberculosis has been recognized for many years now. It has also been realized that the diabetic, particularly uncontrolled, is more susceptible to the development of pulmonary tuberculosis than his non-diabetic counterpart.

Objectives: Objective of our study is to compare and analyze pulmonary tuberculosis in patients with diabetes mellitus and in those who do not have.

Methods: Clinical profile and chest radiograph results of 40 diabetics with pulmonary tuberculosis and 40 cases of pulmonary tuberculosis without diabetes were studied, compared and analyzed.

Results: Male preponderance of the disease was noted in both test and control group and peak incidence of the disease was noted in the age group of 50-59yrs in the test while in control group peak occurrence was in the age group 19-29. Weight loss was significantly high in test group when compared to control group. Majority of people in the test and control had anemia. Majority of the patients in our study had poor glucose control. Cavitary lesion was most common lesion found in both test and control group followed by fibrosis. Tuberculosis tends to occur predominantly at the lower lung fields in patients with diabetes when compared to non-diabetics.

Interpretation and conclusion: Majority of patients in the test and control group presented to us with fever and cough. Weight loss was significantly high in test group when compared to control group. In most of the cases in our study diabetes mellitus was diagnosed before the development of tuberculosis. Majority of our patients had poorly controlled blood sugars, presenting complaints of the patients are not much altered by diabetes. Lower lobe involvement is more common in diabetes with tuberculosis. Early diagnosis and properly monitored regimen is the only time tested answer to this problem.
\end{abstract}

Keywords: diabetes mellitus; pulmonary tuberculosis

\section{Introduction}

Tuberculosis (TB) is now the world's foremost cause of deaths from a single infectious agent. More than 5.8 million new cases were reported to the World Health Organization (WHO) in 2009 with estimated 9.4 million new cases. In 2008 there were 1.7 million estimated deaths from TB. The economic impact of disease by way of direct and indirect costs of contact investigations, costs of TB screening and preventive therapy programs, costs of hospital and institutions infection control programs and costs to patients in lost income, is enormous. An increasing number of cases converting to multi drug resistant tuberculosis could escalate these costs dramatically ${ }^{[1]}$.

The earliest evidence of tuberculosis (TB) in man and animals is provided by bone finds, mainly fragments of vertebrae, showing the gibbus typical of tuberculous Pott's disease. The oldest examples of spinal TB, in the form of fossil bones, date back to about 8000BC ${ }^{[2]}$.

The common risk factors for tuberculosis include poor social circumstances, alcoholism, diabetes mellitus, immigrant population, no previous BCG vaccination and HIV infection ${ }^{[3]}$. The frequency of tuberculosis occurrence in patients of diabetes mellitus (DM) is reported to be 3-4 times than that in non-diabetics. Pulmonary complications of diabetes mellitus are not as well recognized as those involving the cardiovascular, renal, ophthalmologic and neurologic systems ${ }^{[4]}$.

The risk of tubercular infection in diabetes is difficult to assess because of lack of prospective studies. Furthermore, the predisposition of diabetes patients to tubercular infection is not yet well documented. The determinants causing the illness will be discussed further in assessing the magnitude of the risk of tubercular infection in diabetes mellitus. 


\section{Objectives}

To study, compare and analyze pulmonary tuberculosis in patients with diabetes mellitus and in those who do not have.

\section{Methodology}

\section{Source of data}

Patients diagnosed to have pulmonary tuberculosis and having diabetes mellitus and who are non-diabetic and admitted in NRI Medical College\& Hospital, Chinakakani; during study period from September 2017 to August 2019 fulfilling the inclusion and exclusion criteria.

\section{Method of collection of data}

Data for the proposed study was collected in a pretested proforma which included various socioeconomic parameters like age, sex, occupation, religion, income, etc. 80 cases were selected on the basis of simple random sampling out of which 40 cases of pulmonary tuberculosis with diabetes mellitus form the test group and 40 cases with pulmonary tuberculosis without diabetes mellitus after fulfilling the inclusion and exclusion criteria form the control group in our study.

Inclusion criteria: Patients with pulmonary tuberculosis who are known diabetics and non-diabetics.

Exclusion criteria: Patients with HIV, Immuno suppression from malignancy, cytotoxic therapy, corticosteroid therapy and end stage renal disease.

\section{The following investigations are done to assess the above} study

1. Complete blood picture

2. Routine urine analysis

3. FBS, PPBS

4. Blood urea

5. Serum creatinine

6. Chest X-ray PA View

7. Sputum AFB

8. HIV antibodies detected by ELISA

9. Glycosylated hemoglobin

10. Pleural fluid analysis (if indicated)

11. Fine needle aspiration biopsy and / Biopsy of enlarged lymph nodes (if indicated)

12. CT Thorax (if indicated)

\section{Statistical methods applied}

Following statistical methods were applied in the present study.

- Chi-square test

- Odds ratio

\section{Results}

A clinical, biochemical, hematological and radiological evaluation of 40 cases of pulmonary tuberculosis with diabetes mellitus and 40 cases of pulmonary tuberculosis without diabetes was done.
Table 1: Distribution of the sample by groups and age groups

\begin{tabular}{|c|c|c|c|}
\hline \multirow{2}{*}{ Age (in years) } & \multicolumn{2}{|c|}{ Group } & \multirow{2}{*}{ Total } \\
\cline { 2 - 3 } & Test & Control & \\
\hline \multirow{2}{*}{$19-29$} & 2 & 12 & 14 \\
& $5 \%$ & $30 \%$ & $17.5 \%$ \\
\hline \multirow{2}{*}{$30-39$} & 6 & 5 & 11 \\
& $15 \%$ & $12.5 \%$ & $13.75 \%$ \\
\hline \multirow{2}{*}{$40-49$} & 8 & 10 & 18 \\
& $20.0 \%$ & $25 \%$ & $22.5 \%$ \\
\hline \multirow{2}{*}{$50-59$} & 14 & 6 & 20 \\
& $35 \%$ & $15.0 \%$ & $25 \%$ \\
\hline \multirow{2}{*}{$60-69$} & 6 & 6 & 12 \\
& $15 \%$ & $15 \%$ & $15 \%$ \\
\hline \multirow{2}{*}{$70+$} & 4 & 1 & 5 \\
& $10 \%$ & $2.5 \%$ & $6.25 \%$ \\
\hline \multirow{2}{*}{ Total } & 40 & 40 & 80 \\
& $100.0 \%$ & $100.0 \%$ & $100.0 \%$ \\
\hline \multicolumn{3}{|c|}{}
\end{tabular}

In the present study, the number of patients above the age of 40 in test group were $80 \%$ and peak incidence was in the age groups of 50-59 which was 350 and it was $20 \%$ in the age group 40-49 and 15\% in 60-69 while in control group peak incidence was in the age group 19-29 which was 30\%.

Table 2: Distribution of test and control according to sex

\begin{tabular}{|c|c|c|c|}
\hline \multirow{2}{*}{ Sex } & \multicolumn{2}{|c|}{ Group } & \multirow{2}{*}{ Total } \\
\hline & Test & Control & \\
\hline Female & 14 & $\begin{array}{c}5 \\
12.5 \%\end{array}$ & $\begin{array}{c}19 \\
23.75 \%\end{array}$ \\
\hline Male & 26 & $\begin{array}{c}35 \\
87.5 \%\end{array}$ & $\begin{array}{c}61 \\
76.25 \%\end{array}$ \\
\hline Total & $\begin{array}{c}40 \\
100.0 \% \\
\end{array}$ & $\begin{array}{c}46 \\
100.0 \% \\
\end{array}$ & $\begin{array}{c}80 \\
100.0 \% \\
\end{array}$ \\
\hline
\end{tabular}

$P<0.05$ Odds ratio 3.769

In the present study, the number of patients above the age of 40 in test group were $80 \%$ and peak incidence was in the age groups of 50-59 which was 350 and it was $20 \%$ in the age group 40-49 and 15\% in 60-69 while in control group peak incidence was in the age group 19-29 which was 30\%. In our study the total number of males in test group was $65 \%$ while females were and in controls males were still more in number compared to test i.e. $87.5 \%$ and females were only $12.5 \% \mathrm{P}$. value was found to be significant and odds ratio was 3.769 .

Table 3: Duration of cough

\begin{tabular}{|c|c|c|c|}
\hline \multirow{2}{*}{ Duration of cough } & \multicolumn{2}{|c|}{ Group } & \multirow{2}{*}{ Total } \\
\hline & Test & Control & \\
\hline $15 d$ & $\begin{array}{c}15 \\
37.5 \%\end{array}$ & $\begin{array}{c}15 \\
37.5 \%\end{array}$ & $\begin{array}{c}30 \\
37.5 \%\end{array}$ \\
\hline 30d & $\begin{array}{c}9 \\
22.5 \% \\
\end{array}$ & $\begin{array}{c}10 \\
25 \% \\
\end{array}$ & $\begin{array}{c}19 \\
23.75 \% \\
\end{array}$ \\
\hline $45 d$ & $\begin{array}{c}3 \\
7.5 \% \\
\end{array}$ & $\begin{array}{c}1 \\
2.5 \% \\
\end{array}$ & $\begin{array}{c}4 \\
5 \% \\
\end{array}$ \\
\hline $180 d$ & 10 & 12 & $\begin{array}{c}22 \\
27.5 \% \\
\end{array}$ \\
\hline 365 & $\begin{array}{c}3 \\
7.5 \% \\
\end{array}$ & $\begin{array}{c}1 \\
2.5 \% \\
\end{array}$ & $\begin{array}{c}4 \\
5 \% \\
\end{array}$ \\
\hline $365+$ & - & $\begin{array}{c}1 \\
2.5 \% \\
\end{array}$ & $\begin{array}{c}1 \\
1.25 \% \\
\end{array}$ \\
\hline Total & $\begin{array}{c}40 \\
100 \%\end{array}$ & $\begin{array}{c}40 \\
100 \%\end{array}$ & $\begin{array}{c}80 \\
1000\end{array}$ \\
\hline
\end{tabular}


In the present study, number of patients who were having cough of more 30 days duration was $62.5 \%$ in test group and also in the control group.

Table 4: Distribution of Fever in Test and Control Group

\begin{tabular}{|c|c|c|c|}
\hline \multirow{2}{*}{ Fever } & \multicolumn{2}{|c|}{ Group } & \multirow{2}{*}{ Total } \\
\cline { 2 - 3 } & Test & Control & \\
\hline \multirow{2}{*}{ Present } & 36 & 35 & 71 \\
& $90 \%$ & $87.5 \%$ & $88.75 \%$ \\
\hline \multirow{2}{*}{ Absent } & 4 & 5 & 9 \\
& $10 \%$ & $12.5 \%$ & $11.25 \%$ \\
\hline \multirow{2}{*}{ Total } & 40 & 40 & 80 \\
& $100 \%$ & $100 \%$ & $100 \%$ \\
\hline
\end{tabular}

$P>.05$ Odds ratio 1.285

$90 \%$ in the test group had fever but the same in control group was almost same i.e. $87.5 \%$. $\mathrm{P}$ value was found to be not significant.

Table 5: Distribution of Hemoptysis in Test and Control Group

\begin{tabular}{|c|c|c|c|}
\hline \multirow{2}{*}{ Haemoptysis } & \multicolumn{2}{|c|}{ Group } & \multirow{2}{*}{ Total } \\
\cline { 2 - 3 } & Test & Control & \\
\hline \multirow{2}{*}{ Present } & 5 & 3 & 8 \\
& $12.5 \%$ & $7.5 \%$ & $10 \%$ \\
\hline \multirow{2}{*}{ Absent } & 35 & 37 & 72 \\
& $87.5 \%$ & $92.5 \%$ & $90 \%$ \\
\hline \multirow{2}{*}{ Total } & 40 & 40 & 80 \\
& $100 \%$ & $100 \%$ & $100 \%$ \\
\hline
\end{tabular}

$P>.05$ Odds ratio 1.76

Haemoptysis was present in only $12.5 \%$ with diabetes and $7.5 \%$ without diabetes.

Table 6: Distribution of Breathlessness in Test and Control Group

\begin{tabular}{|c|c|c|c|}
\hline \multirow{2}{*}{ Breathlessness } & \multicolumn{2}{|c|}{ Group } & \multirow{2}{*}{ Total } \\
\cline { 2 - 3 } & Test & Control & \\
\hline \multirow{2}{*}{ Present } & 9 & 8 & 17 \\
& $22.5 \%$ & $20 \%$ & $21.25 \%$ \\
\hline \multirow{2}{*}{ Absent } & 31 & 32 & 63 \\
& $77.5 \%$ & $80 \%$ & $78.75 \%$ \\
\hline \multirow{2}{*}{ Total } & 40 & 40 & 80 \\
& $100 \%$ & $100 \%$ & $100 \%$ \\
\hline
\end{tabular}

$P>.05$ Odds ratio 1.16

$22.5 \%$ presented to us with breathlessness in test group while the same in control was $20 \%$. P value was $>.05$ odds ratio of 1.16 .

Table 7: Distribution of Chest pain in Test and Control Group

\begin{tabular}{|c|c|c|c|}
\hline \multirow{2}{*}{ Chest pain } & \multicolumn{2}{|c|}{ Group } & \multirow{2}{*}{ Total } \\
\cline { 2 - 3 } & Test & Control & \\
\hline \multirow{2}{*}{ Present } & 2 & & 2 \\
& $5 \%$ & & $2.5 \%$ \\
\hline \multirow{2}{*}{ Absent } & 38 & 40 & 78 \\
& $95 \%$ & $100 \%$ & $97.5 \%$ \\
\hline \multirow{2}{*}{ Total } & 40 & 40 & 80 \\
& $100 \%$ & $100 \%$ & $100 \%$ \\
\hline$P>.1$ & \multicolumn{3}{l}{} \\
\end{tabular}

Those having chest pain in test group was $5 \%$ and none among the control group had chest pain.
Table 8: Distribution of weight loss in Test and Control Group

\begin{tabular}{|c|c|c|c|}
\hline \multirow{2}{*}{ Weight Loss } & \multicolumn{2}{|c|}{ Group } & \multirow{2}{*}{ Total } \\
\cline { 2 - 3 } & Test & Control & \\
\hline \multirow{2}{*}{ Present } & 35 & 15 & 50 \\
& $87.5 \%$ & $37.5 \%$ & $62.5 \%$ \\
\hline \multirow{2}{*}{ Absent } & 5 & 25 & 30 \\
& $12.5 \%$ & $62.5 \%$ & $37.5 \%$ \\
\hline \multirow{2}{*}{ Total } & 40 & 40 & 80 \\
& $100 \%$ & $100 \%$ & $100 \%$ \\
\hline
\end{tabular}

$P>.001$ Odds ratio 11.66

Weight loss was significantly high in test group when compared to control group and it was $87.5 \%$ in patients with diabetes and $37.5 \%$ in control. $\mathrm{P}$ value was found to be significant with odds ratio of 11.66 .

Table 9: Distribution of Wheezing in Test and Control Group

\begin{tabular}{|c|c|c|c|}
\hline \multirow{2}{*}{ Wheezing } & \multicolumn{2}{|c|}{ Group } & Total \\
\cline { 2 - 4 } & Test & Control & \\
\hline \multirow{2}{*}{ Present } & 6 & 14 & 20 \\
& $15 \%$ & $35 \%$ & $25 \%$ \\
\hline \multirow{2}{*}{ Absent } & 34 & 26 & 60 \\
& $85 \%$ & $65 \%$ & $75 \%$ \\
\hline \multirow{2}{*}{ Total } & 40 & 40 & 80 \\
& $100 \%$ & $100 \%$ & $100 \%$ \\
\hline
\end{tabular}

$P<.05$ odds ratio .3277

Patients presented with wheeze were more in control group i.e. $35 \%$ and in test it was $15 \%$. This may be due to the fact that majority of control were smokers. Here also p was found to be significant i.e. $\mathrm{p}<.05$ with odds ratio 0.3277 .

Table 10: Past history of tuberculosis in Test and Control Group

\begin{tabular}{|c|c|c|c|}
\hline \multirow{2}{*}{ Past history of tuberculosis } & \multicolumn{2}{|c|}{ Group } & Total \\
\cline { 2 - 4 } & Test & Control & \\
\hline \multirow{2}{*}{ Present } & 22 & 10 & 32 \\
& $55 \%$ & $25 \%$ & $40 \%$ \\
\hline \multirow{2}{*}{ Absent } & 18 & 30 & 48 \\
& $45 \%$ & $75 \%$ & $60 \%$ \\
\hline \multirow{2}{*}{ Total } & 40 & 40 & 80 \\
& $100 \%$ & $100 \%$ & $100 \%$ \\
\hline
\end{tabular}

$P<$.OI Odds ratio 3.66

$55 \%$ of patients in test group had past history of tuberculosis and 2500 of control had the same. $\mathrm{P}$ value was found to be significant with Odds ratio 3.66

Table 11: Family history of tuberculosis in Test and Control Group

\begin{tabular}{|c|c|c|c|}
\hline \multirow{2}{*}{ Family history of Tuberculosis } & \multicolumn{2}{|c|}{ Group } & \multirow{2}{*}{ Total } \\
\cline { 2 - 4 } & Test & Control & \\
\hline \multirow{2}{*}{ Present } & 5 & 3 & 8 \\
& $12.5 \%$ & $7.5 \%$ & $10 \%$ \\
\hline \multirow{2}{*}{ Absent } & 35 & 37 & 72 \\
& $87.5 \%$ & $92.5 \%$ & 900 \\
\hline \multirow{2}{*}{ Total } & 40 & 40 & 80 \\
& $100 \%$ & $100 \%$ & $100 \%$ \\
\hline
\end{tabular}

$P>$.l Odds ratio 1.76

$12.5 \%$ in the test group and $7.5 \%$ in the control group had family history of tuberculosis. P value was found to be not significant for the same odds ratio of 1.76 . 
Table 12: Past history of DM in Test and control Group

\begin{tabular}{|c|c|c|c|}
\hline \multirow{2}{*}{ Past history of DM } & \multicolumn{2}{|c|}{ Group } & \multirow{2}{*}{ Total } \\
\cline { 2 - 3 } & Test & Control & \\
\hline \multirow{2}{*}{ Present } & 29 & - & 29 \\
& $72.5 \%$ & - & $36.25 \%$ \\
\hline \multirow{2}{*}{ Absent } & 11 & 40 & 51 \\
& $27.5 \%$ & $100 \%$ & 63.75 \\
\hline \multirow{2}{*}{ Total } & 40 & 40 & 80 \\
& $100 \%$ & $100 \%$ & $100 \%$ \\
\hline
\end{tabular}

$P<.001$

$72.5 \%$ of patients had diabetes prior to hospital admission and $27.5 \%$ were detected to have diabetes in our hospital in test group.

Table 13: Duration of Diabetes

\begin{tabular}{|c|c|c|c|}
\hline \multirow{2}{*}{ Duration of DM } & \multicolumn{2}{|c|}{ Group } & \multirow{2}{*}{ Total } \\
\cline { 2 - 3 } & Test & Control & \\
\hline \multirow{2}{*}{ NO DM } & - & 40 & 40 \\
& & $100 \%-$ & $50 \%$ \\
\hline \multirow{2}{*}{$1 \mathrm{Yr}$} & 16 & - & 16 \\
& $40 \%$ & - & $20 \%$ \\
\hline \multirow{2}{*}{$1.01-5 \mathrm{Yr}$} & 14 & - & 14 \\
& $35 \%$ & - & $17.5 \%$ \\
\hline \multirow{2}{*}{$5.01-10 \mathrm{Yr}$} & 6 & - & 6 \\
& $15 \%$ & - & $7.5 \%$ \\
\hline \multirow{2}{*}{$10+$} & 4 & - & 4 \\
& $10 \%$ & & $5 \%$ \\
\hline \multirow{2}{*}{ Total } & 40 & 40 & 80 \\
& $100 \%$ & $100 \%$ & $100 \%$ \\
\hline
\end{tabular}

In most of the cases in our study diabetes mellitus was diagnosed before the development of tuberculosis. $72.5 \%$ had diabetes Prior to the onset of tuberculosis $40 \%$ were detected to had diabetes less than one year and 1-5 Year Duration for the same in 35\% while 15\% of patients were in 5.01-10 year group and had diabetes more than ten years duration.

Table 14: Distribution of Smoking in Test and control Group

\begin{tabular}{|c|c|c|c|}
\hline \multirow{2}{*}{ Past history of DM } & \multicolumn{2}{|c|}{ Group } & \multirow{2}{*}{ Total } \\
\cline { 2 - 3 } & Test & Control & \\
\hline \multirow{2}{*}{ Yes } & 20 & 27 & 47 \\
& $50 \%$ & $67.5 \%$ & $58.75 \%$ \\
\hline \multirow{2}{*}{ No } & 20 & 13 & 33 \\
& $50 \%$ & $32.5 \%$ & 41.25 \\
\hline \multirow{2}{*}{ Total } & 40 & 40 & 80 \\
& $100 \%$ & $100 \%$ & $100 \%$ \\
\hline
\end{tabular}

\section{$P>$. l Odds ratio 0.48}

20 out of 26 males in test group and 27 out of 35 males in control group were smokers in our study. That's $50 \%$ of test group and $67.5 \%$ of control were smokers. $P$ value was found to be of no significance with odds ratio of 0.48 This may be due to the fact that cases were randomly selected and since both test and control both had tuberculosis and since the test group had diabetes too, they might have been counseled about the ill effects of smoking and most of them might had quit smoking.
Table 15: Distribution of Clubbing in Test and Control Group

\begin{tabular}{|c|c|c|c|}
\hline \multirow{2}{*}{ Clubbing Group } & \multicolumn{2}{|c|}{ Group } & \multirow{2}{*}{ Total } \\
\cline { 2 - 3 } & Test & Control & \\
\hline \multirow{2}{*}{ Present } & 4 & 3 & 7 \\
& $10 \%$ & $7.5 \%$ & $8.75 \%$ \\
\hline \multirow{2}{*}{ Absent } & 36 & 37 & 73 \\
& $90 \%$ & $92.5 \%$ & 91.25 \\
\hline \multirow{2}{*}{ Total } & 40 & 40 & 80 \\
& $100 \%$ & $100 \%$ & $100 \%$ \\
\hline
\end{tabular}

$P>$.l Odds ratio 1.37

Clubbing was noted in $10 \%$ of the patients with diabetes and pulmonary tuberculosis and in those without diabetes was $7.5 \%$. $\mathrm{P}$ value was found to be not significant for the same.

Table 16: Distribution of Lymphadenopathy in Test and Control Group

\begin{tabular}{|c|c|c|c|}
\hline \multirow{2}{*}{ Lymphadenopathy group } & \multicolumn{2}{|c|}{ Group } & \multirow{2}{*}{ Total } \\
\cline { 2 - 3 } & Test & Control & \\
\hline \multirow{2}{*}{ Present } & 4 & 6 & 10 \\
& $10 \%$ & $15 \%$ & $12.5 \%$ \\
\hline \multirow{2}{*}{ Absent } & 36 & 34 & 70 \\
& $90 \%$ & $85 \%$ & $87.5 \%$ \\
\hline \multirow{2}{*}{ Total } & 40 & 40 & 80 \\
& $100 \%$ & $100 \%$ & $100 \%$ \\
\hline$P>$.5 Odds ratio 0.6296 & \multicolumn{3}{|c}{} \\
\hline
\end{tabular}

$10 \%$ in the test group and $15 \%$ in the control group had cervical lymph node enlargement.

Table 17: Distribution of Oral Candidiasis in Test and Control Group

\begin{tabular}{|c|c|c|c|}
\hline \multirow{2}{*}{ Oral Candidiasis Group } & \multicolumn{2}{|c|}{ Group } & \multirow{2}{*}{ Total } \\
\hline & Test & Control & \\
\hline Present & $\begin{array}{c}2 \\
5 \%\end{array}$ & - & $\begin{array}{c}2 \\
2.5 \%\end{array}$ \\
\hline Absent & $\begin{array}{c}38 \\
95 \%\end{array}$ & $\begin{array}{c}40 \\
100 \%\end{array}$ & $\begin{array}{c}78 \\
97.5 \%\end{array}$ \\
\hline Total & $\begin{array}{c}40 \\
100 \%\end{array}$ & $\begin{array}{c}40 \\
100 \%\end{array}$ & $\begin{array}{c}80 \\
100 \%\end{array}$ \\
\hline
\end{tabular}

In present study $5 \%$ of the patient with diabetes and pulmonary tuberculosis had oral candidiasis and none among the control group had the same.

Table 18: Hemoglobin in Test and control Group

\begin{tabular}{|c|c|c|c|}
\hline \multirow{2}{*}{ Hb Group } & \multicolumn{2}{|c|}{ Group } & \multirow{2}{*}{ Total } \\
\cline { 2 - 3 } & Test & Control & \\
\hline \multirow{2}{*}{$<7 \mathrm{gm} / \mathrm{dl}$} & 2 & 1 & 3 \\
& $5 \%$ & $2.5 \%$ & $3.75 \%$ \\
\hline \multirow{2}{*}{$7.01-10 \mathrm{gm} / \mathrm{dl}$} & 17 & 21 & 38 \\
& $42.5 \%$ & $52.5 \%$ & $47.5 \%$ \\
\hline \multirow{2}{*}{$10.01-12 \mathrm{gm} / \mathrm{dl}$} & 16 & 13 & 29 \\
& $40 \%$ & $32.5 \%$ & $36.25 \%$ \\
\hline \multirow{2}{*}{$12+$} & 5 & 5 & 10 \\
& $12.5 \%$ & $12.5 \%$ & $12.5 \%$ \\
\hline \multirow{2}{*}{ Total } & 40 & 40 & 80 \\
& $100 \%$ & $100 \%$ & $100 \%$ \\
\hline$P>0.5$ & \multicolumn{3}{|c}{} \\
\cline { 2 - 3 } & & &
\end{tabular}


$87.5 \%$ of patients belonging to test group had anemia and among them $5 \%$ had severe anemia $(\mathrm{Hb}<7 \mathrm{gm} / \mathrm{dl})$ and $40 \%$ had mild ( $\mathrm{Hb} 10-12 \mathrm{gm} / \mathrm{dl}$ ) 42.5\% (Hb<7-10gm/dl) had moderate anemia and anemia in control group was $87.5 \%$ and among them 2.5\% had severe anemia, 52.5\% had moderate anemia and $32.5 \%$ had mild anemia.

Table 19: Distribution of Total count and Lymphocyte Count in Test and Control Group.

\begin{tabular}{|c|c|c|c|}
\hline & & $\mathbf{N}$ & Mean \\
\hline \multirow{2}{*}{ TC } & \multirow{2}{*}{ Test Control } & 40 & 9518 \\
\hline & & 40 & 7117 \\
\hline \multirow{2}{*}{ L } & \multirow{2}{*}{ Test Control } & 40 & 38.6 \\
\hline & & 40 & 41.2 \\
\hline
\end{tabular}

The total white cell count in our study showed an average value of 9518 in test and 7117 in control group and lymphocytes were an average of $38.6 \%$ in test and $41.2 \%$ in control.

Table 20: Distribution of ESR in Test and Control Group.

\begin{tabular}{|c|c|c|c|}
\hline \multirow{2}{*}{ ESR } & \multicolumn{2}{|c|}{ Group } & \multirow{2}{*}{ Total } \\
\cline { 2 - 3 } & Test & Control & \\
\hline \multirow{2}{*}{$<20$} & 4 & 7 & 11 \\
& $10 \%$ & $17.5 \%$ & $13.75 \%$ \\
\hline \multirow{2}{*}{$20-50$} & 10 & 2 & 12 \\
& $25 \%$ & $5 \%$ & $15 \%$ \\
\hline \multirow{2}{*}{$50.01-100$} & 22 & 28 & 50 \\
& $55 \%$ & $70 \%$ & $62.5 \%$ \\
\hline \multirow{2}{*}{$100+$} & 4 & 3 & 7 \\
& $10 \%$ & $7.5 \%$ & $8.75 \%$ \\
\hline \multirow{2}{*}{ Total } & 40 & 40 & 80 \\
& $100 \%$ & $100 \%$ & $100 \%$ \\
\hline$P>.05$ & & & \\
& & \multicolumn{3}{c}{} \\
\end{tabular}

$55 \%$ of patients in this study in test group showed an erythrocyte sedimentation rate between 51 to 100 and 25\% had values between $20-50 \mathrm{~mm} / \mathrm{hr}$. Values above 100 were noted in $10 \%$ of patients. The same in control was $70 \%$ and $5 \%$ respectively and $7.5 \%$ has ESR above 100 . Hence we conclude ESR was relatively higher in Control group than test.

Table 21: Distribution of FBS in Test Group.

\begin{tabular}{|c|c|c|}
\hline FBS & Frequency & Percent \\
\hline$<100$ & 2 & 5 \\
\hline $101-126$ & 2 & 5 \\
\hline$>126$ & 36 & 90 \\
\hline Total & 40 & 100 \\
\hline
\end{tabular}

The fasting blood sugar value of $>126$ was seen in $90 \%$ and only $10 \%$ had the same $<126 \mathrm{mg} \%$.

Table 22. Distributi0n of PPBs in Test group

\begin{tabular}{|c|c|c|}
\hline FBS & Frequency & Percent \\
\hline$<140$ & 2 & 5 \\
\hline $141-200$ & 18 & 45 \\
\hline $200+$ & 20 & 50 \\
\hline Total & 40 & 100 \\
\hline
\end{tabular}

PPBS only $5 \%$ had $<140 \mathrm{mg} \%$ and $45 \%$ had values between 140 and 200 and 50\% had the same above 200mg\%.
Table 23: Distribution of HbA1C in Test Group

\begin{tabular}{|c|c|c|}
\hline \multirow{2}{*}{ HbA1C } & Group & \multirow{2}{*}{ Total } \\
\cline { 2 - 2 } & Test & 9 \\
\hline \multirow{2}{*}{$<7$} & 9 & $22.5 \%$ \\
\hline \multirow{2}{*}{$<7$} & $22.5 \%$ & 31 \\
& 31 & $77.5 \%$ \\
\hline \multirow{2}{*}{ Total } & $77.5 \%$ & 40 \\
& 40 & $100 \%$ \\
\hline
\end{tabular}

Majority of patients in our study had poor glucose control. Only $22.5 \%$ had $\mathrm{HbAlC}<7$ and $77.5 \%$ had the same $>7$.

Table 24: Distribution of Sputum Positivity in Test and Control Group

\begin{tabular}{|c|c|c|c|}
\hline \multirow{2}{*}{ Sputum Group } & \multicolumn{2}{|c|}{ Group } & \multirow{2}{*}{ Total } \\
\cline { 2 - 3 } & Test & Control & \\
\hline \multirow{2}{*}{ Sputum Negative } & 13 & 9 & 22 \\
& $32.5 \%$ & $22.5 \%$ & $27.5 \%$ \\
\hline \multirow{2}{*}{ Sputum Positive } & 27 & 31 & 58 \\
& $67.5 \%$ & $77.5 \%$ & $72.5 \%$ \\
\hline \multirow{2}{*}{ Total } & 40 & 40 & 80 \\
& $100 \%$ & $100 \%$ & $100 \%$ \\
\hline
\end{tabular}

$P>.1$ Odds ratio 1.658

Sputum AFB was demonstrated in 67.5\% in test and77.5\% in control and sputum was negative for AFB in $32.5 \%$ of test and $22.5 \%$ of control and here $\mathrm{P}$ value was not significant.

Table 25: Analysis of Chest X-ray in Test and Control Group

\begin{tabular}{|c|c|c|c|}
\hline \multirow{2}{*}{ X-ray } & \multicolumn{2}{|c|}{ Group } & \multirow{2}{*}{ Total } \\
\hline & Test & Control & \\
\hline $\mathrm{RU} / \mathrm{L}$ & $\begin{array}{c}9 \\
22.5 \%\end{array}$ & $\begin{array}{c}15 \\
375 \%\end{array}$ & $\begin{array}{c}24 \\
30 \%\end{array}$ \\
\hline $\mathrm{LU} / \mathrm{L}$ & $\begin{array}{c}6 \\
15 \%\end{array}$ & $\begin{array}{c}9 \\
22.5 \%\end{array}$ & $\begin{array}{c}15 \\
18.75 \%\end{array}$ \\
\hline $\mathrm{RL} / \mathrm{L}$ & $\begin{array}{c}2 \\
5 \%\end{array}$ & - & $\begin{array}{c}2 \\
2.5 \%\end{array}$ \\
\hline $\mathrm{LL} / \mathrm{L}$ & $\begin{array}{c}2 \\
5 \%\end{array}$ & $\begin{array}{c}1 \\
2.5 \%\end{array}$ & $\begin{array}{c}3 \\
3.75 \%\end{array}$ \\
\hline B/L Apical & $\begin{array}{c}2 \\
5 \% \\
\end{array}$ & $\begin{array}{c}14 \\
35 \% \\
\end{array}$ & $\begin{array}{c}16 \\
20 \% \\
\end{array}$ \\
\hline $\mathrm{B} / \mathrm{L} \mathrm{L} / \mathrm{L}$ & $\begin{array}{c}8 \\
20 \%\end{array}$ & - & $\begin{array}{c}8 \\
10 \%\end{array}$ \\
\hline L Extensive & $\begin{array}{c}4 \\
10 \%\end{array}$ & - & $\begin{array}{c}4 \\
5 \%\end{array}$ \\
\hline Rt Extensive & $\begin{array}{c}3 \\
7.5 \%\end{array}$ & - & $\begin{array}{c}3 \\
3.75 \%\end{array}$ \\
\hline Rt mid Zone & $\begin{array}{c}2 \\
5 \% \\
\end{array}$ & $\begin{array}{c}1 \\
2.5 \% \\
\end{array}$ & $\begin{array}{c}3 \\
3.75 \% \\
\end{array}$ \\
\hline B/L Extensive & $\begin{array}{c}2 \\
5 \%\end{array}$ & - & $\begin{array}{c}2 \\
2.5 \%\end{array}$ \\
\hline Total & 40 & 40 & 80 \\
\hline
\end{tabular}

Table 26: Distribution of upper and lower lobe involvement in test and control

\begin{tabular}{|c|c|c|c|}
\hline \multirow{2}{*}{ Chest X-Ray } & \multicolumn{2}{|c|}{ Group } & \multirow{2}{*}{ Total } \\
\cline { 2 - 3 } & Test & Control & \\
\hline Upper Lobe & $\begin{array}{c}17 \\
30.9 \%\end{array}$ & $\begin{array}{c}38 \\
69.09 \%\end{array}$ & 55 \\
\hline Lower Lobe & $\begin{array}{c}12 \\
\text { N2.3\% }\end{array}$ & $\begin{array}{c}1 \\
7.69 \%\end{array}$ & 13 \\
\hline$P<.05$ & \multicolumn{2}{|l}{} \\
\hline
\end{tabular}


Right-sided lung lesions were noted in $40 \%$ of the cases in test group and left sided lesions in $30 \%$ of the cases and $30 \%$ had bilateral lesion. Right sided lung lesions in $40 \%$ in control group and left sided lesions in $25 \%$ and $35 \%$ had bilateral lesion in the control group. Overall $30 \%$ in the test had lower lobe involvement and only $2.5 \%$ had lower lobe involvement in the control group. In total lower lobe involvement, 92.3\%cases were from test group and 7.69\%from control group. After excluding right, left and bilateral extensive involvement, comparison was done between test and control group based up on upper and lower lobe involvement as shown in the table and $\mathrm{p}$ value was found to be significant to conclude lower lobe involvement were more common in diabetics than non-diabetics.

Table 27: Chest X-ray in Test and Control Group

\begin{tabular}{|c|c|c|c|}
\hline \multirow{2}{*}{ Chest X-Ray } & \multicolumn{2}{|c|}{ Group } & \multirow{2}{*}{ Total } \\
\cline { 2 - 3 } & Test & Control & \\
\hline \multirow{2}{*}{ Cavity } & 13 & 20 & 33 \\
& $32.5 \%$ & $50 \%$ & $41.25 \%$ \\
\hline \multirow{2}{*}{ Fibrosis } & 11 & 13 & 24 \\
& $27.5 \%$ & $32.5 \%$ & $30 \%$ \\
\hline \multirow{2}{*}{ Consolidation } & 7 & 4 & 11 \\
& $17.5 \%$ & $10 \%$ & $13.75 \%$ \\
\hline \multirow{2}{*}{ Pleural effusion } & - & 2 & 2 \\
& & $5 \%$ & $2.5 \%$ \\
\hline \multirow{2}{*}{ Hydro pneumothorax } & 1 & - & 1 \\
& $2.5 \%$ & & $1.25 \%$ \\
\hline \multirow{2}{*}{ Bronchiectasis } & 4 & 1 & 5 \\
& $10 \%$ & $2.5 \%$ & $6.25 \%$ \\
\hline \multirow{2}{*}{ Fibrocavity } & 4 & - & 4 \\
& $10 \%$ & & $5 \%$ \\
\hline \multirow{2}{*}{ Total } & 40 & 40 & 80 \\
& $100 \%$ & $100 \%$ & $100 \%$ \\
\hline
\end{tabular}

Chest X-ray showed cavity lesions in 32.5\% in test and 50\% in cont.-oL fibrosis in $27.5 \%$ test and $32.5 \%$ in control. Other lesions noted are consolidation $17.5 \%$ in test and $10 \%$ control, pleural effusion $5 \%$ in control hydroneumothorax $2.5 \%$ in test, bronchiectasis in $10.0 \%$ in test and $2.5 \%$ in control group.

Table 28: Complications in Test Group

\begin{tabular}{|c|c|c|}
\hline & Yes & No \\
\hline \multirow{2}{*}{ Retinopathy } & 10 & 30 \\
& $25 \%$ & $75 \%$ \\
\hline \multirow{2}{*}{ Nephropathy } & 9 & 31 \\
& 22.5 & $77.5 \%$ \\
\hline \multirow{2}{*}{ Neuropathy } & 6 & 34 \\
& $15 \%$ & $85 \%$ \\
\hline \multirow{2}{*}{ Diabetic Ketoacidosis } & 3 & 37 \\
& $7.5 \%$ & $92.5 \%$ \\
\hline Ischemic Heart & 3 & 37 \\
Disease & $7.5 \%$ & $92.5 \%$ \\
\hline \multirow{2}{*}{ Peripheral Vascular disease } & 3 & 37 \\
& $7.5 \%$ & $92.5 \%$ \\
\hline Cerebro Vascular accident & - & - \\
\hline Deep Vein thrombosis & - & - \\
\hline
\end{tabular}

Retinopathy was seen in $25 \%$ and nephropathy was seen $22.5 \%$ in of Test group, $15 \%$ had neuropathy, $7.5 \%$ presented to us with diabetic ketoacidosis and7.5\% Ischemic heart disease.7.5\% had peripheral vascular disease.
Table 29: Distribution in Test Group received Insulin/OHA

\begin{tabular}{|c|c|c|c|}
\hline \multirow{2}{*}{ Insulin/OHA } & \multicolumn{2}{|c|}{ Group } & \multirow{2}{*}{ Total } \\
\hline & Test & Control & \\
\hline $\mathrm{NO}$ & & $\begin{array}{c}40 \\
100 \% \\
\end{array}$ & $\begin{array}{c}40 \\
50 \% \\
\end{array}$ \\
\hline Insulin & $\begin{array}{c}27 \\
67.5 \% \\
\end{array}$ & & $\begin{array}{c}27 \\
33.75 \% \\
\end{array}$ \\
\hline Ins + OHA & $\begin{array}{c}13 \\
32.5 \% \\
\end{array}$ & & $\begin{array}{c}13 \\
16.25 \% \\
\end{array}$ \\
\hline Total & $\begin{array}{c}40 \\
100 \% \\
\end{array}$ & $\begin{array}{c}40 \\
100 \% \\
\end{array}$ & $\begin{array}{c}80 \\
100 \% \\
\end{array}$ \\
\hline
\end{tabular}

$67.5 \%$ of our patients were receiving insulin alone and $32.5 \%$ were treated with both insulin and oral hypoglycemic agents.

\section{Discussion}

Data for the proposed study was collected in a pretested proforma which include various parameters like age, sex, occupation, religion, income, etc. 80 cases were on the basis of simple random sampling out of which 40 consecutive cases tuberculosis with diabetes mellitus form the test group and 40 cases of pulmonary tuberculosis without diabetes mellitus after fulfilling the inclusion and exclusion criteria were the control group in our study.

In our study the total number of males in test group was $65 \%$ while females were $35 \%$ and in controls males were still more in number compared to test i.e. $87.5 \%$ and females were only $12.5 \%$. P value was found to be significant and Odds ratio was 3.769.

Other studies have shown that, the prevalence as well as incidence of tuberculosis is higher among males than among females. Male sex and increasing age were significant risk factors for TB in both univariate and multivariate analyses ${ }^{[5]}$. A retrospective epidemiologic analysis of sex-specific tuberculosis incidence rates in San Francisco from 19911996 shown that in the study period, the male to female incidence rate ratio was $2.1^{[6]}$.

Patel JC showed a similar ratio of male to female. In the 179 cases he studied, $76 \%$ were males and $24 \%$ females ${ }^{[7]}$.

Tuberculosis incidence among male diabetics was than that of female diabetics as reported by Kim SJ ${ }^{[8]}$.

All the above studies showed an increased incidence of the disease in males as compared to females and our study also noted the same.

The high incidence of disease in males is possibly due to fact that both tuberculosis and diabetes are more common in males.

In the present study, the number of patients above the age of 40 in test group were $80 \%$ and peak incidence was in the age groups of $50-59$ which was $35 \%$ and it was $20 \%$ in the age group $40-49$ and $15 \%$ in $60-69$ while in control group peak incidence was in the age group 19-29 which was 30\%. A study by Chaimowicz Z F on the age transition of tuberculosis incidence and mortality in Brazil shown that the incidence of tuberculosis has begun to shift to the older population. This shift results from the decline in the annual risk of infection as well as the demographic transition. An increase in reactivation tuberculosis in older people is expected ${ }^{[9]}$. 
Deshmukh reported that $14 \%$ of the tuberculosis patients over the 40 had diabetes ${ }^{[10]}$.

Euro TB started in 1996 with the objective to improve the contribution of public health surveillance to tuberculosis control in Europe and the standardization of tuberculosis surveillance methods. This study shows that age distribution of the total number of cases could be described according to recommended age Groups in 32 countries reporting a total of 107096 cases. Among these cases, 4\% were reported in children (1\% in children under five, $3 \%$ in the 5 to 14 age), $77 \%$ In adolescents and adults less than 65 years old $(11 \%$ in the 15 to 24 years age group, $18 \%$ in the 25 to 34 group, $20 \%$ in the 35 to 44 group, $15 \%$ in the 45 to 54 group, $13 \%$ in the 55 to 64 group) and $19 \%$ in patients aged 65 or more [11].

This study also showed a higher incidence of tuberculosis in diabetic people over the age of 40 Yrs. In this study the highest incidence was in the age group of 50-59 years.

In the present study, number of patients who were having cough of more than 30 days duration was $60 \%$ in test group and also in the control group.

$22.5 \%$ presented to us with breathlessness in test group while the same in control was $20 \%$. \& $90 \%$ in the test group had fever but the same in control group was almost same that is $87.5 \%$.

Haemoptysis were present in only $12.5 \%$ with diabetes and $7.5 \%$ without diabetes and those having chest pain was 5\% but none among the control group had chest pain.

Patients presented with wheeze were more in control group i.e. $35 \%$ and in test it was $15 \%$. This may be due to the fact that majority of control people were smokers. P was found to be significant i.e. $P<.05$ with odds ratio 3277 .

Weight loss was significantly high in test group when compared to control group and it was $87.5 \%$ in patients with diabetes and $37.5 \%$ in control and $\mathrm{P}$ value was found to be significant with odds ratio of II .667. In a study done in Ethiopian diabetic patients with tuberculosis and most common symptoms of tuberculosis were fever (80.5\%), and cough $(70.5 \%)^{[12]}$.

In our study also percentage of cough and fever was high and there was no significant difference between test and control group based on symptoms with which they present to us. P value was not significant for fever, breathlessness and cough. 55\% of patients in test group had past history of tuberculosis and $25 \%$ of control had the same and $12.5 \%$ in the test group and $7.5 \%$ in the control group had family history of tuberculosis too and p value was significant for both. $72.5 \%$ of patients had diabetes prior to hospital admission and $27.5 \%$ were detected to be diabetic in our hospital. 20 out of 26 males in test group and 27 out of 35 males in control group were smokers in our study, i.e., 50\% of the test group and $67.5 \%$ of control were smokers.

Clubbing was noted in $10 \%$ of the patients with diabetes and pulmonary tuberculosis and in $7.5 \%$ of those without diabetes. There was no significant difference between the test and control and $\mathrm{P}$ value was $>$.l and is not significant.

A study by Macfarlane JJ, Ibrahim M, Tor-Agbidye. S on the importance of finger clubbing in pulmonary tuberculosis, shown that finger clubbing was observed in $21 \%$ of 70 adult Nigerian patients presenting with pulmonary tuberculosis. These patients had a significantly higher incidence of haemoptysis and they also showed a significantly lower body weight and serum albumin than those without clubbing. Their chest $\mathrm{X}$-rays revealed larger ities and at 2 months the mortality of the patients with finger clubbing (40\%) was very much higher than of those without (5.5\%). It is suggested that finger clubbing is of value in assessing patients with pulmonary tuberculosis because it helps to identify those with severe destructive disease ${ }^{[13]}$.

$10 \%$ in the test group and $15 \%$ in the control group had cervical lymph node enlargement. In present study $5 \%$ of the patient with diabetes and pulmonary tuberculosis had oral candidiasis and none among the control group had the same.

$87.5 \%$ of patients belonging to test group had anemia and among them 5\% had severe anemia ( $\mathrm{HB}<7 \mathrm{gm} / \mathrm{dl}$ ) and 40\%had mild (HB 10-12gmJdl) and 42.5\% (HB 7-10gm/dl) had moderate anemia and the same in control group was 87.5\% and among them $2.5 \%$ had severe anemia, $52.5 \%$ had moderate anemia and $32.5 \%$ had mild anemia. Morris et al. observed anemia in 60 percent of the patients; males being more frequently affected than females. (54) In our study it was higher.

The cause of low haemoglobin level in pulmonary tuberculosis is considered to be multifactorial. Bone narrow iron has been found to be decreased in some studies. Similarly; serum iron and total iron binding capacity have been observed to be decreased in patients with pulmonary tuberculosis and anaemia compared to those without anaemia. Further, bone marrow non-haeme iron was found to be greater, suggesting decreased release of marrow iron stores and suppression of erythropoiesis by inflammatory response mediators. Ebrahim recently found that the erythropoietin level was low in patients with both pulmonary tuberculosis and anaemia and suggested that blunted erythropoietin response in these patients was due to the inhibitory effect of tumor necrosis factor $-\alpha[$ TNF- $\alpha]$ [14].

$55 \%$ of patients in this study in test group showed an erythrocyte Sedimentation rate between 51 to 100 and 25\% had values between 20 to $50 \mathrm{~mm} / \mathrm{hr}$. Values about 100 were noted in $10 \%$ of patients. The same in control was $70 \%$ and $5 \%$ respectively and $7.5 \%$ had ESR above 100 . Hence to conclude ESR was relatively higher in control group than test.

The ESR is a nonspecific test and it can be elevated in numerous conditions. It is not of any diagnostic value. It is the manifestation of a generalized disease or of tissue destruction. Single determination of the value is of no significance and repeated tests have some practical value. The test also has some practical value in the prognosis of chronic pulmonary tuberculosis cases under treatment.

In most of the cases in our study diabetes mellitus was diagnosed before the development of tuberculosis. $72.5 \%$ had diabetes prior to the onset of tuberculosis $40 \%$ were detected to have diabetes less than one year and 1-5 year duration for the same in $35 \%$ while $15 \%$ of patients were in 5-10 yr. group and $10 \%$ had diabetes in this study was more than 10 yrs duration.

The duration of diabetes is significant because there is an increased opportunity for infections with increased duration of diabetes. The result of the present study is comparable to other studies.

Majority of the patients in our study had poor glucose control. The fasting blood sugar value of $>126$ was seen in $90 \%$ and only $10 \%$ had the same $<126 \mathrm{mg} \%$ while PPBS only $5 \%$ had PPBS < 140mg\% and 45\% had value between 
140 and 200 and $50 \%$ had the same above 200mg\%. only $22.5 \%$ had HbAIC $<7$ and $77.5 \%$ had the same $>7$.

Jawad et al. reported glucose intolerance in as many as 49 per cent of the patients with active tuberculosis, with impaired glucose tolerance in 29 per cent and diabetes mellitus in $20 \%$. After anti tuberculosis therapy, 50 per cent of them had normalization of glucose intolerance. Some authors reported an association between severity of tuberculosis and abnormal glucose tolerance.

However, no association has been found -93-with age, family history of tuberculosis, ethnicity or duration of treatment. A number of postulations have been made to explain the increased prevalence of diabetes mellitus in tuberculosis. Nicholas suggested that whenever two diseases are associated, a reciprocal relationship is expected. Others have suggested that occult glucose intolerance predisposes to tuberculosis infection. Most tuberculosis patients in developing countries have malnutrition and low body mass index. Malnutrition has been postulated as a modulatory factor in the pathogenesis of diabetes mellitus. Roychowdhury and Sen have suggested tuberculosis of the pancreas to be a possible cause of glucose intolerance. Another suggested possibility is stress induced diabetes mellitus which can occur in major illnesses like tuberculosis [15].

Sputum AFB was demonstrated in $67.5 \%$ in test and $77.5 \%$ in control and sputum was negative for AFB in $32.5 \%$ of test and $22.5 \%$ in control group. Sosman and Steidl had made an observation that tuberculosis tends to occur predominantly at the lower lung fields in patients with diabetes, as also shown by Weaver $\mathrm{R}^{[16]}$.

However, Parmer $\mathrm{M}$ and Berger $\mathrm{H}$ showed that lower lung field involvement is an infrequent location of pulmonary tuberculosis, occurring in 7 percent or less of patients with active pulmonary tuberculosis ${ }^{[17,18]}$.

Cavity lesions $32.5 \%$ were the most common type of lesions noted followed by fibrosis $27.5 \%$, consolidation in $17.5 \%$ hydroneumothorax 2.5\%. 10\% in test had bronchiectasis and fibro cavity respectively. In control group cavity lesions were $50 \%$, fibrosis $32.5 \%$, consolidation in $10 \%$ and pleural effusion in $5 \%$ were noticed, while $2.5 \%$ had Bronchiectasis.

Right-sided lung lesions were noted in $40 \%$ of the cases in test group and left sided lesions in $30 \%$ of the cases and $30 \%$ had bilateral lesion. Right-sided lung lesions were noted in $40 \%$ in control group and left sided lesions in $25 \%$ of the cases and $35 \%$ had bilateral lesion in the control group. $30 \%$ in the test had lower lobe involvement and only $2.5 \%$ had lower lobe involvement control group.

A more recent study of Perez-Guzman et al. who reviewed the radiographs of 192 diabetic patients with tuberculosis, also reported this finding ${ }^{[19]}$. Moris JT, found that multiple lobe involvement is the predominant presentation of pulmonary tuberculosis in diabetics ${ }^{[20]}$.

Retinopathy was seen in of test group, nephropathy was seen in $22.5 \%$, while $15 \%$ had neuropathy, $7.5 \%$ presented to us with diabetic ketoacidosis, $7.5 \%$ had Ischemic heart disease, $7.5 \%$ had peripheral vascular disease.

$7.5 \%$ of our patients were receiving insulin alone and 32.5\% were treated with both insulin and oral hypoglycemic agents. Our study correlates with most of the above radiological studies in regards to the side of lesion, site of lesion, extent of lesion as well as nature of radiological patterns.

\section{Conclusion}

In our study the total number of males in test group were $65 \%$ while females were $35 \%$ and in controls males were still more in number compared to test i.e.87.5\% and females were only $12.5 \%$.

This study also showed a higher occurrence of tuberculous diabetics in people over the age of 40 yrs. In the study the highest incidence was in the age group of 50-59 yrs.

Majority of the patients in the test and control group presented to us with fever and cough. Weight loss was significantly high in test group when compared to control group.

Clubbing was noted in $10 \%$ of the patients with diabetes and pulmonary tuberculosis and in those without diabetes was 7.5\%. Majority of people in the test and control group had anemia. ESR was relatively higher in control group than test.

In most of the cases in our study diabetes mellitus was diagnosed before the development of tuberculosis. Majority of the patients in our study had poor glucose control. Cavitary lesion was most common lesion found in both test and control group followed by fibrosis, extensive lesions were seen in $22.5 \%$ of the test group.

Upper lobe lesions were noted in $42.5 \%$ in test group while the same in control was $95 \%, 10 \%$ in the test group has got unilateral lower lobe involvement while $2.5 \%$ in the control has the same and bilateral lower lobe involvement was in $20 \%$ of test, the same was none in control group. Tuberculosis tends to occur predominantly at the lower lung fields in patients with diabetes.

\section{Acknowledgment}

The author is thankful to Department of General Medicine, NRI Medical College\& Hospital for providing all the facilities to carry out this work.

\section{Conflict of Interest}

None

\section{Financial Support}

Nil

\section{References}

1. Bates JH, Stead WW. The history of tuberculosis as a global epidemic. The Medical Clinics of North America 1993;77(6):1205-1217.

2. Herzog Basel H. History of Tuberculosis. International journal of thoracic medicine 1998;65(1):5-15.

3. Gaude GS. Pulmonary complications of diabetes mellitus. Medicine Update 1998, 221-5

4. Singh SK, Samaria SK, Matah JC. Pulmonary tuberculosis and diabetes mellitus. Update on Respiratory Medicine 1997, 385-389.

5. Arora VK, Sarin R, Revised National Tuberculosis Control Programme Indian Perspetive. The Indian Journal of Chest Diseases \& Allied Sciences 2000;42:21-26.

6. Per Gustafson, Victor Gomes, Cesaltina Vieira S. Paulo Rabna, Remonie and risk factors in an urban community in sub-Saharan Africa. International journal of epidemiology 33(1), 163-172.

7. Patel JC, Desouza, Cheryl, Jigjini SS. Diabetes and tuberculosis. Indian Journal of Tuberculosis 1977;24:155-158. 
8. Kim SJ. Incidence of pulmonary tuberculosis among diabetes. Tubercle and lung Disease 1995;76:529-533.

9. Chaimowicz ZF. Age transition of tuberculosis: incidence and morality in Brazil, Revista De Saude Publica 2001;35(1):81-87

10. Deshmukh MD, Master TB, David JG Tripathy S. Diabetes complicated by Pulmonary Tuberculosis. Journal of J.J. Group of Hospitals and grant Medical College 1966, 11(2).

11. Martinez AN, Rhee N, small PM, Behr MA. Sex Differences in the epidemiology of tuberculosis in san Fransisco. International journal of tuberculosis and lung disease 2000;4(1):26-31.

12. Feleke Y, Abdulkadir J, Aderaya G. Prevalence and clinical features of tuberculosis in Ethiopian diabetic patients. East Afr. Med J 1999;76(7);361-64.

13. Macfarlene JJ, Ibrahim M, Tor Agbidye S. The important of finger clubbing in pulmonary tuberculosis. Tubercle 1979;60(1):45-48.

14. Sharma SK, Mohan A, Dutta S, Ray R, Gill SS. Haemotological manifestations of tuberculosis. In: Tuberculosis, 1st edition 370-379.

15. Sharma SK, Mohan A, Dutta S, Ray R, Gill SS. Endocrine implications of tuberculosis, In: tuberculosis, 1st edition 386-395

16. Weaver R. Unusual radiographic presentation of pulmonary tuberculosis in diabetic patients. Am Rev Respiratory Disease 1974;109:162-163.

17. Parmer M. Lower lung field tuberculosis. Am Rev Respiratory Disease 1967;96:31013.

18. Berger $H$. Lower lung field tuberculosis. Chest 1974;65:522-26.

19. Perez-Guzman C, Torres-Cruz A. Villarreal-Velarde H. Atypical radiological images of pulmonary tuberculosis in 192 diabetic patients: A comparative study. Int J Tubere Lund Dis 2001;5:455-461.

20. Morris JT. Pulmonary tuberculosis in diabetics. Chest 1992;102:539-541. 